\title{
HYDROGENATED OILS.*
}

ANDREW CAMPBELL.

Broadly speaking, the chemical combinations presented in fixed oils and fats are glycerides of various fatty acids. The formulæ of these characteristic acids, again broadly speaking, differ from one another principally in the number of the contained hydrogen atoms, while the physical properties of the various oils seem to be dependent upon the underlying character and proportions of these acids.

Oleic and stearic acids are the most commonly presented of these substances and the physical difference caused by these two constituents is largely manifested in that oleic acid combinations give oils and fats of soft or liquid consistency while stearic acid, as a rule, is characteristic of the harder fats.

The chemical formula recognized for oleic acid is $\mathrm{C}_{18} \mathrm{H}_{34} \mathrm{O}_{2}$, while that for stearic acid is $\mathrm{C}_{18} \mathrm{H}_{38} \mathrm{O}_{2}$. Two hydrogen atoms, then, added to oleic acid will transform it into stearic acid. It has long been apparent that such a transformation, if it could be economically accomplished, would be of great commercial importance. The purely chemical possibility of this step was long ago demonstrated, but it has only been within recent years that practical processes, workable under commercial conditions have been devised for carrying out this chemical transformation of oleic into stearic acid or of olein and its related substances into stearin and similar bodies. It might be remarked in passing that this exact problem is very neatly solved in the economy of nature when the steer, fattened, say, on cottonseed meal, gives us tallow and oleo-stearin, but owing to the wastefulness of this process, the modern oil-chemist by his direct methods may well claim to outdo the steer.

The essential feature of all the modern hardening processes is to bring about intimate contact between the oil under treatment and gaseous hydrogen in the presence of a third substance known as a catalyzer. Numerous catalyzers have been proposed, but finely divided metallic nickel is probably the most typical. A great variety is also shown in the forms of apparatus devised for the accomplishment of the process, many of which have been the subjects of patents.

The two greatest apparent fields of usefulness for such a process seem to be the production of edible fats and the bringing into range of soap-making materials vegetable and animal oils which have hitherto been unavailable on account of the relative softness of their products or for certain other technical reasons. Hardened oils will probably find other wide uses in the arts, for example in the manufacture of lubricants, but for the present the production of edible fats and of soap-making materials is of paramount importance in the development of the process.

Two seemingly contradictory statements may be made in regard to hydrogenated oils. One is that their production is quite simple and can be carried out without elaborate or expensive apparatus and the other is that commercial success can be

* Read before the Pittsburgh Branch, A. Ph. A. 
attained only in rather expensive and well-equipped plants. The necessary supply and handling of hydrogen at a reasonable cost are the controlling factors of such a situation.

In the simplest form of apparatus provision only need be made for carrying a stream of hydrogen through the oil in the presence of the catalyzer at a slightly elevated temperature. On the other hand, some of the most complex and elaborate forms of apparatus have been designed and patented in great variety with a view to making the process commercially efficient.

As to catalyzers, metallic nickel seems to be most favored, but palladium is well regarded and platinum, iron and copper have been used. Oxides of these same metals have also been exploited as suitable catalyzers and one of the inventors in the line has patented the use of various organic salts of similar metallic elements. A great variety of schemes have been tried for making the catalyst not by itself but deposited in a fine state of division on the surface of some inert carrying substance. Pumice stone, kieselguhr, charcoal and sawdust have all been used. The production of a good catalyzer requires considerable care and technical skill. In the case of nickel the steps are precipitation of a nickel nitrate solution by means of alkali and the subsequent reduction of the precipitated hydroxide by heating in a current of hydrogen. Particular care is needed in controlling the temperature of the reduction process. Protection from air and moisture is required after reduction and the catalyzers are subject to the peculiar fact that the presence of even very small amounts of chlorine and sulphides greatly depreciates their activity. This is spoken of as "poisoning" the catalyzer.

Inasmuch as the hardening process is only an application of previously known chemical reactions, no basic patents can be sustained on it. Consequently we find that the many patents issued in connection with the matter fall naturally into two classes, those on particular catalyzers and the methods for producing the same and those on apparatus and devices for carrying out the general process. The catalyzer patents are of the most importance and one firm of English soap-makers, Crossfield \& Sons, seems to have made some attempt at monopoly, having acquired the patents on nickel, palladium and platinum. Such an attempt, however, would not seem to be effective since numerous other patents have been issued for the oxides and the Wimmer patents cover the use of organic salts. The oxide patents are mostly held by the combination known in the trade as the Bedford-ErdmanWilliams interests. Then, too, one process has been devised which dispenses entirely with catalyzers and carries out the hydrogenation by the application of hydrogen alone but at comparatively high pressures.

A great variety of fatty oils may be treated with a view to increasing their economic usefulness. The most important, on account of the utility of their hardened products, are the liquid vegetable oils such as cottonseed, corn, sesame, castor and linseed oils and the marine animal oils such as menhaden, fish and whale oils. Cottonseed oil has been the principal product under exploitation, although much work has been done abroad on fish and whale oils. Hardened cottonseed oil yields products of use in the manufacture of lard compounds and butter substitutes and the hardened train oils are equal or superior to the higher-priced tallows for soap makers. 
The question of the safety and healthfulness of the edible products yielded by this method has been carefully investigated and no criticism can stand against them if care is used to eliminate the possible traces of metallic contamination originating from the catalyzing elements. Taste, odor and color of many of the oils are very much improved. Particularly is this true of the disagreeable odor of the marine oils which thorough treatment by hydrogenation seems absolutely to remove. As to this point it is interesting to note that the Japanese chemist, Tsujimoto, has demonstrated that the odor and taste of fish oil instead of being due to impurities, as had been supposed, are really caused by the presence of a characteristic fatty acid, clauponodonic acid, having the formula $\mathrm{C}_{18} \mathrm{H}_{28} \mathrm{O}_{2}$, which by the addition of eight hydrogen atoms becomes stearic acid and loses its odor and taste.

Much has been reported and written about the possible wonderful cheapening of soap makers' materials, but this has been considerably exaggerted, at least for the immediate future. In Germany a perfectly odorless, white, hardened train oil has been offered on the market at 66 marks per 100 kilos, which compares with a price in the same market of 72 marks per 100 kilos for prime boiling tallow. As the process becomes better developed and more widely used very material reductions in the price of the products may be reasonably expected. As has already been indicated, no monopoly of the process is likely to be established, but on the other hand it will not be available for small fat and soap industries, on their own premises, largely on account of the expense necessary to secure the requisite supply of hydrogen at an economical price.

Factories have been established for working the process in Germany and England, while recently a Norwegian-German company has built a factory at Friedrichstad, utilizing the water-power of Hafslund Falls for the electricity needed in the works and for the production of hydrogen by the electrolytic method. This factory is expected to utilize about 300 barrels of oil daily. So far as I am aware, but one commercial project on any considerable scale has been attempted in this line in the United States. This is located at Ivorydale, Ohio, and operates under the name of the American Oil Treating and Hardening Company. A close connection with one of the large soap manufacturing concerns would seem to be indicated, but both edible and inedible hardened fats are advertised and offered by this company.

It is one of the striking facts of modern industry that so large and important developments should proceed from the utilization of such a simple and apparent chemical reaction. One is lead to a remark, which while trite is exceedingly apropos, that only the merest surface of the broad field of chemical invention has thus far been touched, and in spite of all the accomplishments of the past fifty or one hundred years, the future holds most wonderful prospects for development and achievement in chemistry. It is equally true that it is not always the abstruse and complex in chemistry that holds out the greatest possibilities, but frequently some very simple reaction carries the secret of a new industry. 